\title{
Young Women's Misinformation Concerning IT Careers: Exchanging One Negative Image for Another
}

\author{
Donna M. Grant \\ North Carolina Central \\ University, School of Business, \\ Durham, NC, USA \\ grantd@nccu.edu
}

\author{
Linda V. Knight and \\ Theresa A. Steinbach \\ DePaul University, \\ Chicago, IL, USA
}

Iknight@cti.depaul.edu; tsteinbach@cti.depaul.edu

\begin{abstract}
This research reports on the results of a study of 412 girls, ages sixteen through eighteen, in a major Midwestern United States city. The study, which also uncovered unexpected racial differences, found that, contrary to the preponderance of the research evidence, most high school girls say that they do not view those who choose IT careers as being geeks or loners. These results, which also contradict widely held beliefs, suggest the need to reassess resources currently allocated to combat the geek and loner images, particularly in large urban areas. Unfortunately, the results are not as positive as they might seem at first glance. More than half of the girls studied believe that people who choose IT careers are obsessed with computers. This new misinformation, rooted in girls' personal experiences, is likely to prove even more difficult to counter than the geek image that it appears to be replacing.
\end{abstract}

Keywords: misinformation, personal experience, high school girls, IT careers, geek image, loner image, computer obsession

\section{Introduction}

\section{Goal of the Research}

Numerous researchers have indicated that a particular piece of misinformation, the perception of Information Technology (IT) professionals as being geeks and loners, may be one of many explanations for the under-representation of women in Information Technology. In particular, Jepson and Perl (2002) identified a nerdy image of IT people as one of six reasons that girls do not

Material published as part of this publication, either on-line or in print, is copyrighted by the Informing Science Institute. Permission to make digital or paper copy of part or all of these works for personal or classroom use is granted without fee provided that the copies are not made or distributed for profit or commercial advantage AND that copies 1) bear this notice in full and 2) give the full citation on the first page. It is permissible to abstract these works so long as credit is given. To copy in all other cases or to republish or to post on a server or to redistribute to lists requires specific permission and payment of a fee. Contact Publisher@InformingScience.org to request redistribution permission. choose IT careers. Hazzan and Levy (2006) identified a "geeky" and loner image as one of three factors discouraging women from IT careers, positing that women are more likely to be interested in careers involving more interaction with people. Margolis and Fisher (2002) suggested that women are more likely to be affected by the geek stereotype than men are, and thus, when women do not experience an intense obses- 
sion with computers, they are more likely to contemplate whether they really belong in the IT field. Eglash (2002) described the geek identity as not only a gender but also a race concern that acts as a gatekeeper and paradox in the participation of science and technology as it potentially hinders diversity. The purpose of this research was to determine if girls in the United States, ages sixteen through eighteen, at the age when they are making university and career choices, do indeed view IT professionals in this negative way.

\section{Significance of the Issue}

The geek/loner issue is important for multiple reasons. The predicted growth of IT jobs in the United States (Hecker, 2005), the shortage of IT professionals (McGee, 2005), and the underrepresentation of women in the IT field have raised serious concern regarding the US technology workforce in the 21st century (Camp, 1997; Grant, Knight, \& Steinbach, 2006; Holzer, 2006; Lazowska, 2002; Sanders, 2005). According to the employment outlook for $2004-2014$ by the Bureau of Labor and Statistics (Hecker, 2005), computer and mathematical science occupations are projected to increase 30.7 percent, an additional 967,000 jobs. Of the 30 fastest-growing occupations during this time, six are in computer-related disciplines: network systems and data communications analysts, computer application software engineers, computer systems software engineers, network and computer systems administrators, database administrators, and computer systems analysts. A 2005 study by the Society for Information Management (cited in McGee, 2005) lists critical shortages in IT project management and "business domain" experts for 2005 2008. McGee (2005) cites two reasons for the shortage of IT professionals. A 10 percent decline from 10 or 15 years ago in the number of students majoring in technology-related degrees has been estimated. Some universities report upwards of a 50 percent decrease in enrollment in these degrees. As baby-boomer professionals begin retiring, an expertise shortage will exacerbate the situation. There has been an 18.5 percent decline in the percentage of women in the IT workforce since 1996 (Information Technology Association of America, 2005). Women composed 32.4 percent of the total IT workforce in 2004. A third of these women are in administrative occupations such as "data entry keyer" and "computer operator." If these administrative occupations are removed from the calculations, women IT professionals and managers fall to 24.9 percent, virtually the same percentage as in 2002 .

Over the past two decades, the number of young women in the US pursuing careers in Computer and Information Sciences (CIS) has significantly decreased. The National Center of Educational Statistics (2005) reported that in 1984, 32,439 undergraduate students received bachelor's degrees in CIS. Men represented 20,416 of the total (63 percent), while women were 12,023 (37 percent). However, in 2004, 59,488 students received their bachelor's degrees in CIS of which 44,585 (75 percent) were men and 14,903 (25 percent) were women. Thus, the percentage of CIS majors who are female has dropped from 37 percent in 1984 to just 25 percent in 2004. Table 1 provides a list of CIS disciplines reported in the National Center of Educational Statistics. This list reflects a broad definition of the CIS field.

Table 1 - Computer and Information Sciences fields of study

\begin{tabular}{|l|}
\hline Computer and information sciences, general \\
\hline Artificial intelligence and robotics \\
\hline Information technology \\
\hline Computer programming \\
\hline Data processing and data processing technology/technician \\
\hline Information science/studies \\
\hline
\end{tabular}




\begin{tabular}{|l|}
\hline Computer systems analysis/analyst \\
\hline Computer science \\
\hline Data modeling/warehousing and database administration \\
\hline Computer graphics \\
\hline Computer software and media applications, other \\
\hline Computer systems networking and telecommunications \\
\hline System administration/administrator \\
\hline System, networking, and LAN/WAN management/manager \\
\hline Computer and information systems security \\
\hline Web/multimedia management and webmaster \\
\hline Computer/information tech. services admin. and management \\
\hline Computer and information sciences and support services \\
\hline
\end{tabular}

Continued decline in the percentage of women entering the CIS field is a problem both in terms of meeting increased demand for IT workers and because a less diverse workforce produces less diverse, and thus, more impoverished ideas. As Lazowska (2002) stated, "Engineering solutions are enriched and enhanced by the diversity of the engineering teams that create these solutions. A non-diverse engineering workforce inevitably leads to diminished-indeed, improvised engineering solutions" (p. 11).

\section{Background}

\section{Defining the Geek Stereotype}

Margolis and Fisher (2002) describe the Geek Mythology as a stereotype that portrays computer scientists as nerdy and obsessed with computers. Margolis and Fisher began their study at Carnegie Mellon University in 1995. As part of their research, students external to the computer science discipline described their computer science peers as people who were "in love with computers, myopically focused on them to the neglect of all else, living and breathing the world of computing, at the computer 24/7" (p. 65). Margolis and Fisher state the Geek Mythology can be a paradox because 69 percent of the female computer science students and 32 percent of the male students in their study did not agree that they fit this geeky image. AAUW (AAUW Educational Foundation, 2000) states, "Girls tend to imagine that computer professionals live in a solitary, anti-social, and sedentary world" (p. 10). Beyer, Rynes, and Haller's study (2004) identifies the perception of computer science students as "somewhat unsociable and nerdy" (p. 26). Carlson (2006) reports the perception of computer scientists are "the brilliant but socially inept mumblers who could use a few tips on hairstyles and clothes." Several researchers identify the geek image as the nerdy, pocket-protector, male-dominated, computing culture (Miliszewska, Barker, Henderson, \& Sztendur 2006; Newton, 2001; Weibel, 2006). Furthermore, the media continues to perpetuate the geeky, anti-social image of IT professionals (Thomas \& Allen, 2006; Weibel, 2006). "Television and movies continue to depict the IT professional as a nerd, who has no people skills and is only concerned with technical issues" (Thomas \& Allen, 2006, p. 166). Thus, as the quotations in Table 2 reveal, the geek concept in scholarly research has two major elements: (1) a fascination with computers and (2) social awkwardness and isolation. 
Table 2. Defining the Geek Stereotype

\begin{tabular}{|l|l|l|}
\hline Researcher & Year & Quote \\
\hline AAUW & 2000 & $\begin{array}{l}\text { "Girls tend to imagine that computer professionals live in a solitary, } \\
\text { anti-social, and sedentary world" (p. 10). }\end{array}$ \\
\hline Newton & 2001 & $\begin{array}{l}\text { "It could be that either a reality or a perception of geekiness concerning } \\
\text { math and computer obsession in high school is part of the problem" (p. } \\
72 \text { ). }\end{array}$ \\
\hline $\begin{array}{l}\text { Margolis and } \\
\text { Fisher }\end{array}$ & 2002 & $\begin{array}{l}\text { "in love with computers, myopically focused on them to the neglect of } \\
\text { all else, living and breathing the world of computing, at the computer } \\
\text { 24/7" (p. 65). }\end{array}$ \\
\hline Carlson & 2006 & $\begin{array}{l}\text { "the brilliant but socially inept mumbler who could use a few tips on } \\
\text { hairstyles and clothes" (p. 5). } \\
\text { Levzan and } \\
\text { "It has been suggested that the low representation of women in IT re- } \\
\text { sults from the geeky image of IT workers that discourages women from } \\
\text { pursuing tech careers" (p. 8). }\end{array}$ \\
\hline Miliszewska & 2006 & $\begin{array}{l}\text { "popular perception of the male-dominated computing culture, its par- } \\
\text { ticularly masculine character and, often a geek image" (p. 108). }\end{array}$ \\
\hline $\begin{array}{l}\text { Thomas and } \\
\text { Allen }\end{array}$ & 2006 & $\begin{array}{l}\text { "Television and movies continue to depict the IT professional as a nerd, } \\
\text { who has no people skills and is only concerned with technical issues" } \\
\text { (p. 166) }\end{array}$ \\
\hline Weibel & 2006 & $\begin{array}{l}\text { "In many popular movies, computer scientists are usually depicted as } \\
\text { geeks with pocket protectors who are severely socially inept" (p. 1). }\end{array}$ \\
\hline
\end{tabular}

\section{Challenging the Geek Stereotype}

Despite the research cited in the last section, some limited evidence exists that challenges the pervasiveness of the geek and loner stereotypes. Three specific studies contradict in varying ways the ideology that the geeky, antisocial stereotype is a significant deterrent for females. Each of these studies considered a different population segment. Weinberger's study (2004) reported a relatively small percentage of female college students who were alienated by the geek image. Weinberger conducted research from a sample of non-CIS college students and explored the reasons for choosing their college majors and careers. Weinberger's study reported that few, 10 percent of the female non-CIS, students reported they would not choose an IT major because they would be considered, "too serious, nerdy or strange." In their study, Blum and Frieze (2005) revealed a new emerging computer culture that gave the computer science men "the permission to explore their nongeeky characteristics and the women encouragement to be both feminine and computer focused" (p. 114). However, both the Weinberger and the Blum and Frieze studies considered college age students. Only Schott and Selwyn (2000) looked at high school age girls. This research explored the male-dominated, geek and loner stereotype in the United Kingdom. Schott and Selwyn's study concluded with conflicting results. They found that contrary to the stereotypes, the high ICT users were just as socially aware and active as the low ICT users. However, during interviews, the qualitative results found several low ICT users expressing stereotypes toward the high ICT users. Schott and Selwyn postulate that the computer culture is changing due to the ubiquitous use of ICT in their homes and schools over the past decade. Although seemingly not as pervasive as the past, Scott and Selwyn warn that geek stereotypical attitudes remain with some United Kingdom students and must be addressed. 
Table 3. Challenging the pervasiveness of the Geek Stereotype

\begin{tabular}{|l|l|l|l|l|}
\hline Researchers & Year & Participants & Study Location & Results \\
\hline $\begin{array}{l}\text { Schott and } \\
\text { Selwyn }\end{array}$ & 2000 & $\begin{array}{l}117 \text { twelfth } \\
\text { grade students } \\
\text { with a mean age } \\
\text { of 16 years and } \\
\text { months, } 58 \text { fe- } \\
\text { males and 59 } \\
\text { males }\end{array}$ & $\begin{array}{l}\text { Two schools in the } \\
\text { United Kingdom }\end{array}$ & $\begin{array}{l}\text { The top and bottom quartiles } \\
\text { results reported 15 male and 14 } \\
\text { female in the High ICT users } \\
\text { and 17 male and 12 female in } \\
\text { the Low ICT users. In addition, } \\
\text { the High ICT users scored a } \\
\text { high level of significance in the } \\
\text { three social competency scores } \\
\text { of social acceptance, close } \\
\text { friendships, and global self- } \\
\text { worth. }\end{array}$ \\
\hline Weinberger & 2004 & $\begin{array}{l}183 \text { college } \\
\text { women and 33 } \\
\text { men }\end{array}$ & $\begin{array}{l}\text { A large public re- } \\
\text { search university in } \\
\text { the USA. The spe- } \\
\text { cific location was not } \\
\text { stated; however, the } \\
\text { work was funded by } \\
\text { the National Science } \\
\text { Foundation. }\end{array}$ & $\begin{array}{l}\text { Only 10\% of the women } \\
\text { thought, "they would be con- } \\
\text { sidered too serious, nerdy, or } \\
\text { strange" if they were to pursue } \\
\text { an IT career }\end{array}$ \\
\hline $\begin{array}{l}\text { Blum and } \\
\text { Frieze }\end{array}$ & 2005 & $\begin{array}{l}33 \text { Computer Sci- } \\
\text { ence college sen- } \\
\text { iors in the class of } \\
2002,17 \text { women } \\
\text { and 16 men }\end{array}$ & $\begin{array}{l}\text { Carnegie Mellon in } \\
\text { Pittsburgh, Pennsyl- } \\
\text { vania, USA. }\end{array}$ & $\begin{array}{l}\text { Blum and Frieze's study did } \\
\text { not have interview questions } \\
\text { that specifically referred to the } \\
\text { geek stereotype; however, they } \\
\text { received numerous responses } \\
\text { that were contrary to the tradi- } \\
\text { tional, stereotype perceptions. }\end{array}$ \\
\hline
\end{tabular}

\section{Efforts to Overcome the Geek Stereotype}

Perhaps because the vast majority of prior studies support the idea of a geek and loner stereotype discouraging young women from pursuing IT careers, there have been numerous efforts to overcome this stereotype. One recommendation from the AAUW report (AAUW Educational Foundation, 2000) for educating girls in computing for this century is to change the stereotype of the computing culture, to "change the public face of computing." Many universities are conducting workshop sessions, scheduling presentations, and advocating for a change in the computer culture to dispel the geek stereotype. The University of Waterloo developed a weeklong residential Computer Science Seminar for forty high school girls entitled "CS Girls Rock" (Graham \& Latulipe, 2003). The purpose of the seminar was to promote the Computer Science discipline and to challenge the geek stereotype. Laurie Williams (2005) from North Carolina State University has developed a presentation entitled, "Debunking the Geek Stereotype with Software Engineering Education.” Carnegie Mellon University's Women@SCS Outreach Roadshow was created to promote positive images of IT professionals and "to challenge the traditional stereotypes of what and who computer scientists are" (Women@SCS, 2006). Sooriamurthi, Sengupta, Menzel, Moor, Stamm, et al. (2004) from Indiana University identified, "one of the most prominent images in media today is a computer geek" (p. 3). They state that this stereotype drives both men and women away from the computing field and recommended several intervention strategies in the session to dispute the geek stereotype. Indiana University has also developed a student or- 
ganization called "Just Be" to promote computer science fields to and break down the stereotype that students entering those fields are "not just pocket-protector wearing geeks" (Indiana University, 2006). Florida State University is also advocating changing the face of computing. Their message is "You don't have to be a nerdy white guy to be a computer geek. In fact, you can be a woman, a minority, a person with a disability or someone who is downright cool" (Elish, 2006). These widespread efforts to overcome the geek stereotype demonstrate how broadly the existence and powers of the geek image are accepted. Clearly, many universities accept that the geek image is keeping students in general, and women in particular, away from the Information Technology field.

\section{The Purpose of this Study}

Given that significant efforts are being made to combat the geek and loner image among young women, and that the Schott and Selwyn (2000) study at least suggested the possibility that this misconception might be diminishing, the current study was designed to ferret out the truth. It is the first study to specifically address this question with a large number of urban high school girls in the United States. By working with students from a wide variety of academic areas who are making their first major choices about career interests and universities, we hoped to identify resolve the issue of a barrier from the geek / loner image at the point of greatest potential impact.

\section{Research Methodology}

Three hypotheses form the basis for this research:

H1: Most high school girls do not perceive IT workers as geeks.

H2: Most high school girls do not perceive IT workers as loners.

H3: There are no significant racial differences among high school girls' perceptions of IT workers as geeks or loners.

To evaluate these three hypotheses, a survey was administered in the spring of 2006 to eleventh and twelfth grade female students in four high schools in the Chicago area. The average age of the participants was 17. During the survey process, all female eleventh and twelfth graders in each school were encouraged to participate in the survey to ensure a cross-section of girls with different backgrounds and career plans. It was essential for the research to avoid a self-select bias of girls who had a strong interest in computers or computer-related careers. Three of the schools were Chicago public high schools and one school was private. The four high schools selected included girls from a wide variety of ethnic and socioeconomic backgrounds. The first school was a predominately-Hispanic general high school, which is open to all students living in the neighborhood. It is located on Chicago's west side and serves two local largely Hispanic communities (Chicago Public Schools, 2006). The second school was a predominately AfricanAmerican general neighborhood school that is located in a "racially and economically diverse neighborhood" and "offers a rigorous college preparatory curriculum and an accelerated magnet program in partnership with a major research university" (Chicago Public Schools, 2006). The third high school is an all-girls private Catholic Dominican institution with a strong college preparatory curriculum. The last school is a selective enrollment high school with a mixed racial/ethnic background. Admission into this school is highly competitive and requires an entrance exam (Chicago Public Schools, 2006).

The survey had nine sections, with one section focused specifically on the girls' attitudes regarding IT workers. The nine major sections were: 1) basic demographic information, 2) general career questions 3) questions regarding computer courses, 4) computer access and use, 5) attitudes about people who work in IT fields, 6) knowledge about computer and technology careers, 
7) sources of information on IT careers, 8) familiarity with and interest in computer-related careers and 9) attitudes about computer and technology careers. Questions regarding the girls' perception of the characteristics of people who work in IT jobs were developed using a four-point Likert scale. The girls were asked whether they disagree, slightly disagree, slightly agree, or agree with the following two statements: (1) "I think people who choose careers in computers are geeks." and (2) "I think people who choose careers in computers are Loners/antisocial." Two separate questions were asked because of some variation in the meaning of the term geek. As noted earlier, prior academic research sometimes defined geeks as fascinated with computers, sometimes described them as socially inept and isolated, and sometimes identified both characteristics. To insure that we communicated clearly with the girls being studied, we asked two separate questions, one aimed at geeks, and another at loners.

\section{Results}

\section{Demographics}

The sample for this study was comprised of 412 eleventh and twelfth grade girls from four Chicago area high schools. The girls' ethnicities were as follows: 155 Hispanic/Latino girls, 114 African American girls, 107 Caucasian/White girls, 18 Asian/Pacific Islander girls, and 18 girls from a variety of other ethnic backgrounds, as shown in Figure 1.

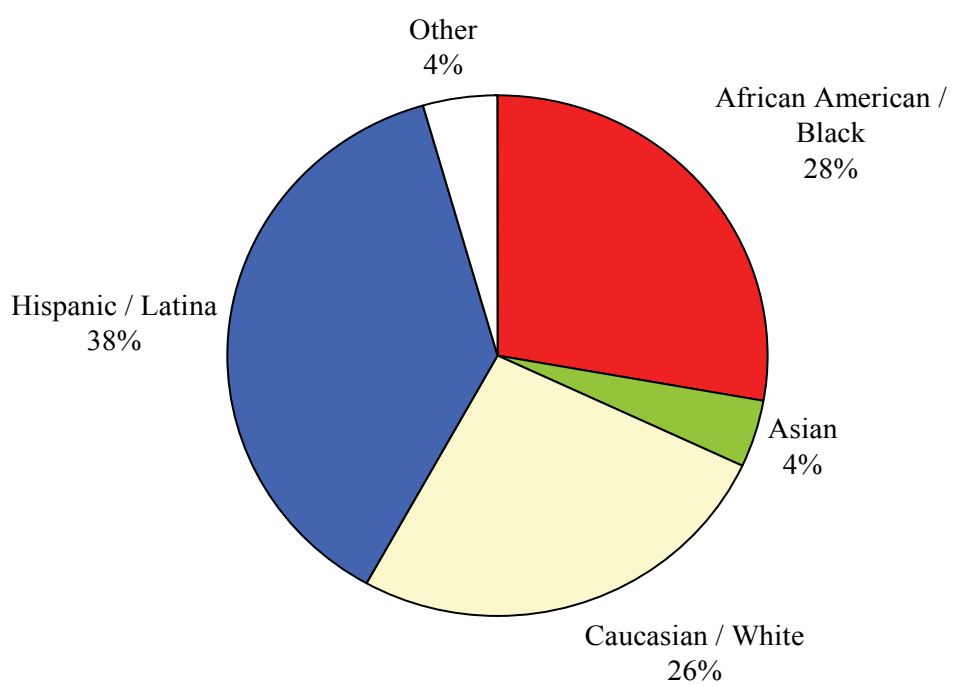

Figure 1: Ethnic Breakdown of Study Participants

\section{H1 and H2: Are IT Workers Perceived as Geeks and Loners?}

Overall results for the geek and the loner questions are shown in Table 4. Using the Chi-squared test of goodness of fit, results for both geeks and loners are significant at the $p<.001$ when compared to an equal distribution that might be expected if results were random. High school girls have a clear opinion about whether IT people are geeks and loners. Interestingly, their opinion does not support the conventional wisdom. Girls are substantially more likely to disagree than agree with the statements that IT workers are geeks or loners. The median value for both geeks and loners was one, "disagree," and more than 81 percent of the study participants either disagreed or disagreed slightly with each of the statements, as shown in Table 4 . Thus, we reject the null hypothesis for both $\mathrm{H} 1$ and $\mathrm{H} 2$. 
Table 4. Are IT workers geeks and loners?

\begin{tabular}{|l|l|l|}
\hline & Agree & Disagree \\
\hline $\begin{array}{l}\text { H1 question: "I think people who choose careers in computers } \\
\text { are geeks" }\end{array}$ & $\begin{array}{l}18.9 \% \\
(n=78)\end{array}$ & $\begin{array}{l}81.1 \% \\
(n=334)\end{array}$ \\
\hline $\begin{array}{l}\text { H2 question: "I think people who choose careers in computers } \\
\text { are loners/antisocial" }\end{array}$ & $\begin{array}{l}18.9 \% \\
(n=78)\end{array}$ & $\begin{array}{l}81.1 \% \\
(n=334)\end{array}$ \\
\hline
\end{tabular}

Upon inspecting Table 4, the observer might be tempted to suspect that all or most girls answered both geek and loner questions identically. This is not the case. There were notable differences apparent in a quick visual check of the girls' responses to the two questions, and this difference is supported by the statistics. Kendall's tau, a common method for comparing two ordinal values, was calculated at a weak .41 with a p value $<.001$ (Wessa, 2006). Thus, it does not appear that there is an important correlation in the geek and loner views. As shown in Figure 2, some girls view IT workers as geeks. Some others view them as loners. Still others view them as both. Most view them as neither.

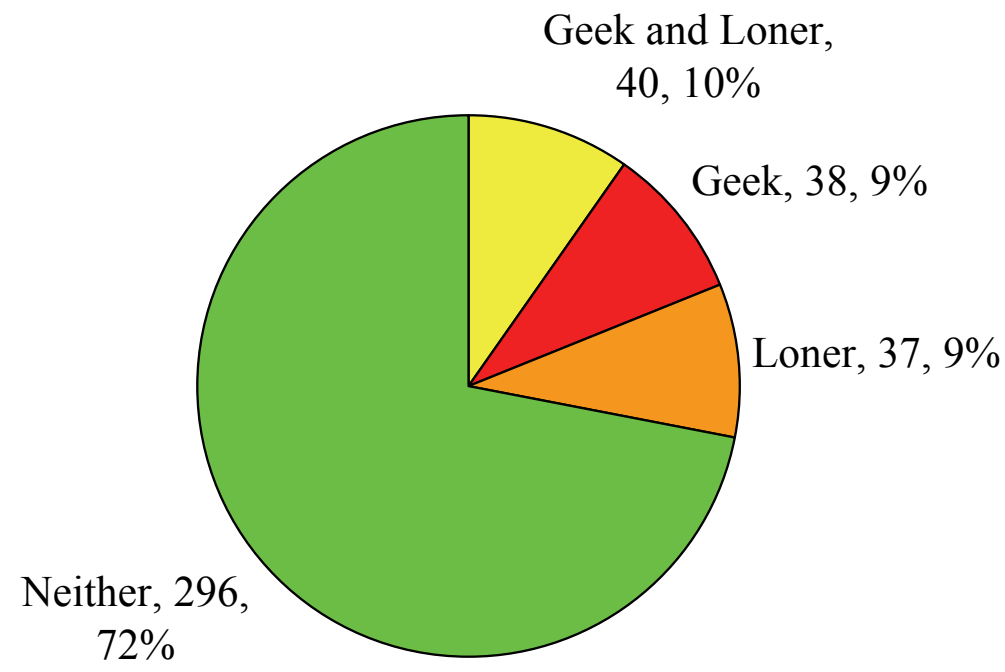

Figure 2. Perceptions of high school girls concerning computer workers

While the geek and loner images did come up in open-ended responses, they did so even less frequently than when the girls were asked a direct question about these stereotypes, as shown in Table 5. This is as would be expected. A freeform response is less likely to elicit a specific response than a question that actually asks about that specific response. Results, in terms of the percentage responding 'YES' to a direct question compared to the percentage responding 'YES' to an indirect, open-ended question, are similar for both groups. 
Table 5: One more time, are IT workers geeks and loners?

\begin{tabular}{|l|c|}
\hline Direct Questions & Yes \\
\hline Computer workers as Geeks & $18.9 \%$ \\
\hline Computer workers are Loners & $18.9 \%$ \\
\hline Open Ended Responses Regarding the Geek Image & \\
\hline $\begin{array}{l}\text { Mention having to deal with dorks, nerds, or geeks as a disad- } \\
\text { vantage of IT careers }\end{array}$ & $1.9 \%$ \\
\hline Open Ended Responses Regarding the Loner Image & \\
\hline Mention lack of interaction with others as a disadvantage & $9.5 \%$ \\
\hline Mention lack of interaction with others as an advantage & $1.2 \%$ \\
\hline Mention lack of social life as a disadvantage & $6.1 \%$ \\
\hline
\end{tabular}

Thus, seventy-two percent of the participants said they did not think IT workers were geeks or loners when asked directly, and an even smaller percentage referred to these characteristics indirectly in their open-ended responses. However, one image of IT workers dissuades the majority of girls from computer work. In a separate objective question, a total of $54.7 \%$ of all respondents agreed when asked, "Do you think people who chose IT careers are obsessed with computers?" Obsession is a negative term that clearly goes beyond the fascination that may be attributed to a computer geek. Some of the girls' freeform answers give insights into this opinion:

- "I think you may grow to depend too much on your computer and not be able to live with out it."

- "You can get obsessed with using the computer, you may want to do everything on the computer and get lazy doing activities."

- "You start to trust something that's not human..."

Thus, it is clear that despite widespread belief to the contrary, neither the geek nor the loner image are held by the majority of high school girls, and they are not major barriers to girls' entry into the Information Technology field. However, the threat of becoming obsessed with computers, or perhaps of having to deal with those who are, is a significant barrier. This concept is explored in more detail in the Discussion section of this paper.

\section{H3: Racial Distinctions}

Figure 3 depicts percentage differences in perceptions of IT workers among various racial groups. The groups are not equal in size. The Asian and Other groups are significantly smaller than the others, with less than twenty participants each, while the three other groups each had well over one hundred girls in each. 


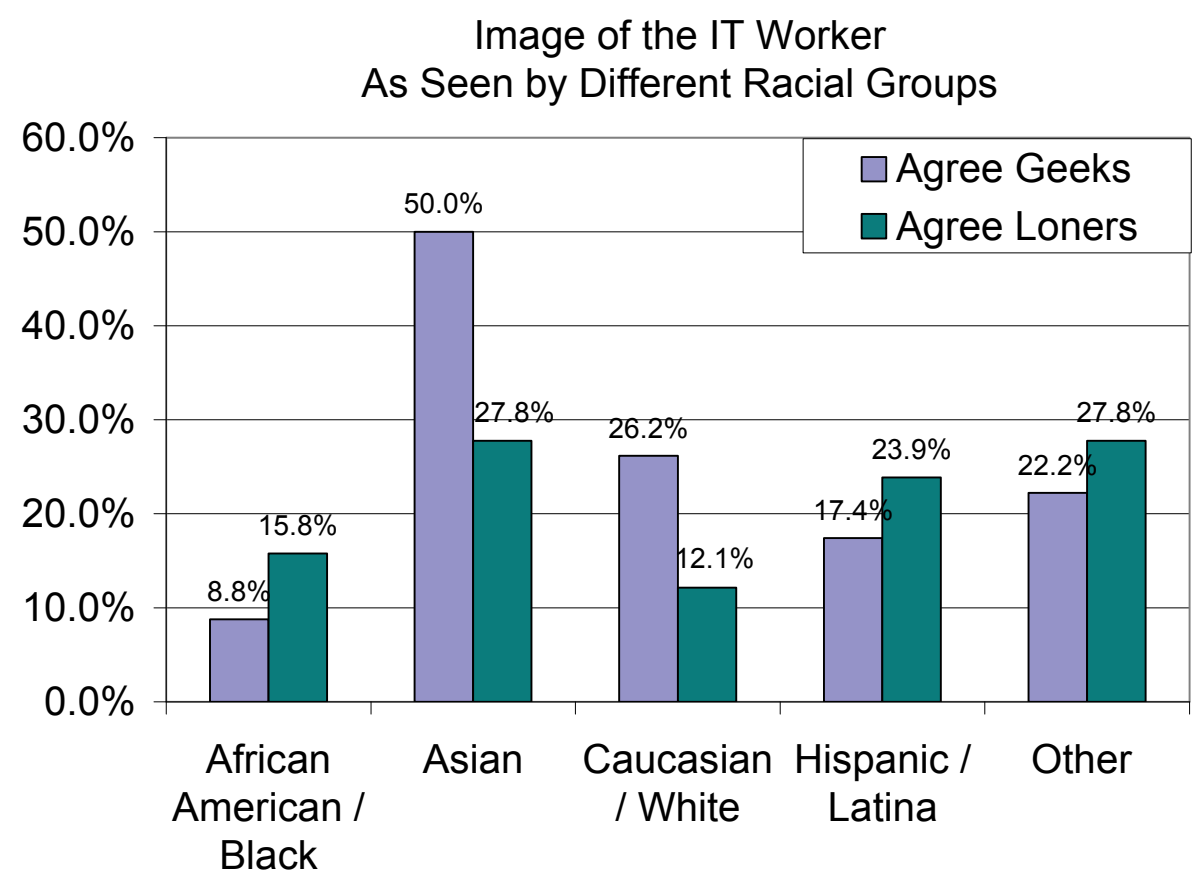

Figure 3. Image of the IT worker by different racial groups

To determine whether these differences in perceptions among the races participating in the study were significant, we ran the Kruskal-Wallis one-way analysis of variance by ranks test for each question. Results are summarized in Table 6.

Table 6. Kruskal-Wallis test results comparing five racial groups

\begin{tabular}{|l|c|c|c|}
\hline & Chi-Square & df & Signif \\
\hline "I think people who choose careers in computers are geeks." & 18.051 & 3 & $<.001$ \\
\hline $\begin{array}{l}\text { "I think people who choose careers in computers are } \\
\text { loners/antisocial" }\end{array}$ & 9.656 & 3 & .022 \\
\hline
\end{tabular}

Although racial differences in responses to the loner question are not significant at the .01 level, the very small $p$ value for the geek question indicates that even though the distributions overlap, there is significant difference in the medians among racial groups. We therefore reject the null hypothesis and conclude that, contrary to our original Hypothesis 3, there are racial differences in terms of how high school girls perceive those who choose computer careers. An exploration of the possible reasons for these differences, and whether they might be the result of other confounding variables, appears in the Discussion section of this report.

From the percentages in Figure 3, African American or Black girls appear most likely to have a non-geek image of IT workers, while Asians appear most likely to accept a geek image. However, further testing was required to determine the specific pairs of racial groups having statistically significant differences with respect to each of the two questions. To detect specific differences among various pairs of races, we conducted Mann-Whitney pair-wise comparisons. Results, shown in Table 7, indicate significant differences at the .01 level for three racial pairs: African American / Black and Asian / Pacific Islander; African American / Black and Caucasian / White; and Asian / Pacific Islander and Hispanic / Latina. 
Table 7. Racial Differences in perception of IT workers as geeks

(* indicates significance at the .01 level)

\begin{tabular}{|c|c|c|c|c|c|}
\hline & $\begin{array}{c}\text { African Amer- } \\
\text { ican / Black } \\
(\mathrm{n}=114)\end{array}$ & $\begin{array}{c}\text { Asian / } \\
\text { Pacific } \\
\text { Islander } \\
(\mathrm{n}=18)\end{array}$ & $\begin{array}{c}\text { Caucasian / } \\
\text { White } \\
(\mathrm{n}=107)\end{array}$ & $\begin{array}{c}\text { Hispanic / } \\
\text { Latina } \\
(\mathrm{n}=155)\end{array}$ & Other \\
\hline $\begin{array}{c}\text { African } \\
\text { American / } \\
\text { Black }\end{array}$ & & $\mathrm{p}<.001^{*}$ & $\mathrm{p}=.003^{*}$ & $\mathrm{p}=.135$ & $\mathrm{p}=.517$ \\
\hline $\begin{array}{c}\text { Asian/ } \\
\text { Pacific } \\
\text { Islander }\end{array}$ & & & $\mathrm{p}=.048$ & $\mathrm{p}=.004^{*}$ & $\mathrm{p}=.074$ \\
\hline $\begin{array}{c}\text { Caucasian / } \\
\text { White }\end{array}$ & & & $\mathrm{p}=.094$ & $\mathrm{p}=.425$ \\
\hline $\begin{array}{c}\text { Hispanic / } \\
\text { Latina }\end{array}$ & & & & $\mathrm{p}=.956$ \\
\hline
\end{tabular}

\section{Discussion}

\section{Geeks and Loners}

As noted earlier, we found that most high school girls do not perceive IT professionals as geeks and loners, upholding our first two hypotheses. This raises the question of where and when the myth derived. Relatively few research studies in the US have addressed the Geek Mythology for girls in a specifically pre-college environment. One notable set of studies on girls and the Geek Mythology was identified in the AAUW series of reports. One of the initial AAUW reports (AAUW Educational Foundation, 1992) addressed the different educational experiences and achievements of girls and boys in reading, writing, mathematics, and science, with very little discussion of computer science or girls participation in the field. However, AAUW's subsequent study (AAUW Educational Foundation, 1998) revealed that "girls comprised of only 17 percent of the AP test takers in computer science and the emergence of computer science as the new boys club" (p. 4) was identified as a major concern. This disinterest of girls regarding computer science in the 1998 study lead to a 10 year research agenda on how to educate girls in the new computing environment. The AAUW 2000 (AAUW Educational Foundation, 2000) report identified the male hacker/geek image and its accompanying computer culture as a significant deterrent for girls, discouraging their entry into the computer field. The AAUW 2000 study consisted of seven focus groups of 70 middle and high school students on the East Coast, and surveys of 892 teachers online. The issue thus arises of why the results of the study being reported upon here are different from the AAUW study 6 years ago. Perhaps, since this survey included 412 girls compared with only 70 girls in the AAUW study, the current results are simply more representative. It is also possible that the location makes a difference; the AAUW study surveyed girls from the East Coast; the location of our survey participants was the Midwest region of the US. Alternatively, Schott and Selwyn's suggestion (2000) that the ubiquitous use of computers and the passage of time have transformed the face of the computer culture to be more inclusive and diverse may be true. Clearly, there are many possible reasons for the decline of the geek and loner image as a major barrier to high school girls' entry into the IT field. However, the cause of the decline is not nearly as important as identifying its existence. If we know that girls are not finding the geek / loner image a disincentive, then we can recognize that we can battle that image less ac- 
tively, and we can turn our limited resources toward other areas, including the extremely important new area of computer obsession or addiction.

We were surprised to find that, while the geek and loner stereotypes are not major barriers to high school girl's entry into the IT field, the possibility of becoming obsessed with computers, or of having to work with those who are obsessed with computers, is. With the word obsession, the simple status of fascination with computers crosses the line into the very negative realm of addiction. We find it likely that while geekiness is a declining concern as computational devices become ever more prevalent, obsession with computers is a growing concern, particularly among high school girls. It is likely that the growing popularity of computer games and of portable electronic devices has resulted in more computer obsession within society in general, and particularly among teenagers, especially teenage boys. We believe that the girls' opinions in our study simply reflect this fact.

\section{Racial Differences}

As stated in the results of $\mathrm{H} 3$, we were surprised to discover the significant differences among the racial groups. As stated earlier, the racial groups were not the same size. The Hispanic, African American, and Caucasian groups had more than one hundred participants, while the Asian group had 18 participants; however, despite the large size differences, there were statistically significant differences among the groups. Figure 4 depicts differences among racial pairs responding to the question of whether those who choose computer careers are geeks. The solid lines connect pairs with a significant difference in their perception of computer workers as geeks. Asians tended to respond significantly different from African Americans and Hispanic/Latinas. Additionally, African American girls responded differently than Caucasians. The possible reasons for these differences may lie deep within different cultures. Possibly some cultures do not view technological advancement as geeky. Possibly what some cultures view as geeky, other cultures view as normal or desirable. Perhaps some cultures are more accepting of diversity and less likely to put pejorative labels on those who are different.

Examining the different elements of the geek definition and determining the impact of a variety of cultures, ethnic backgrounds, and socio-economic factors could provide rich and fascinating results. This study was conducted in a metropolitan city of the Midwest region of the United States. Future research studies could be conducted in rural areas, in other segments of the United States, and in other countries. Additionally, alternative techniques of interviews, focus groups, or case studies could provide the methodologies to more fully dissect the geek definition, if it is indeed further divisible. 


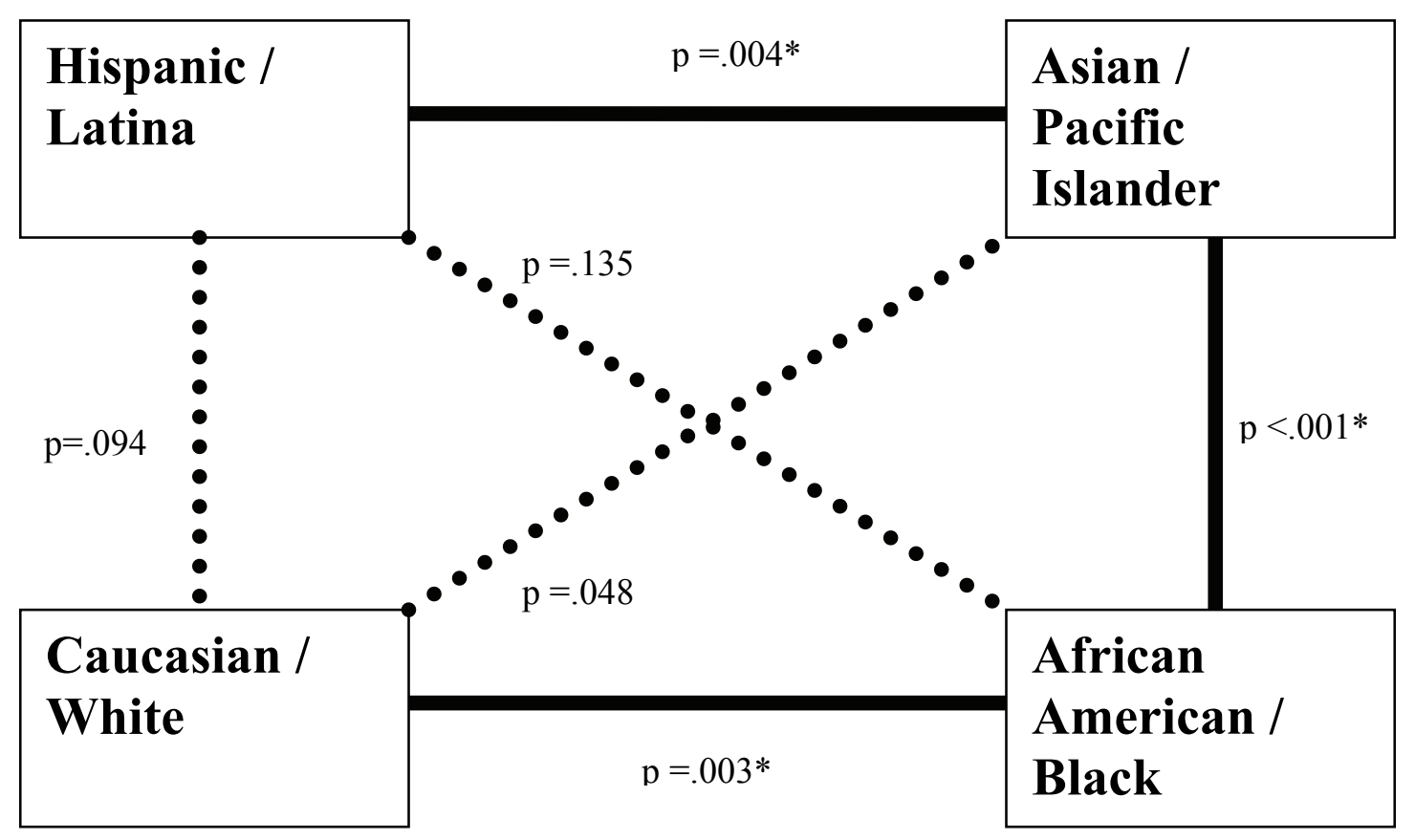

Figure 4. Differences among racial pairs regarding attitude toward computer workers as geeks $(*$ indicates significant difference at the .01 level)

\section{Conclusion}

Consider, in terms of Informing Science, the transformation in high school girls' misconceptions about computer careers, from concern over geekiness to concern over obsession with computers. We can view this transformation as a move from one type of misinformation to another, from a largely unfounded stereotype fueled by the media, to an exaggeration of concrete facts experienced by the girls. Most high school girls have never met a geeky IT worker with a pocket protector, but many have had real personal experiences with computer obsession. They either know someone that they consider to be computer addicted or they themselves have experienced the seductive aspects of computer gaming. Here we have an instance where a new stereotype of computer obsession, primarily based in experience, is likely to be much harder to combat than the old geek stereotype, largely based in the media. There is some evidence in the psychology literature that children tend to be less easily swayed by misinformation about fixed details that they have repeatedly experienced (Connolly \& Lindsay, 1999). Further, university students tend to place highest confidence in misinformation gained through personal experience and considerably less in that gained through the media (Taylor \& Kowalski, 2004). Thus, as high school girls have exchanged media-based misinformation for experience-based misinformation, our job in overcoming that misinformation almost certainly has become significantly more difficult. The geek image may be on its way out, but the obsession threat that replaced it likely will be much harder to counter.

\section{References}

AAUW Educational Foundation (1992). How schools shortchange girls: The AAUW Report. Marlowe \& Company, New York, New York: AAUW Educational Foundation.

AAUW Educational Foundation (1998). Gender gaps: Where schools still fail our children. Washington, D.C.: AAUW Educational Foundation. 
AAUW Educational Foundation (2000). Tech-savvy: Educating girls in the new computer age. Washington D.C.: AAUW Educational Foundation.

Beyer, S., Rynes, K., \& Haller, S. (2004). Deterrents to women taking computer science courses. IEEE Technology and Society Magazine, 23(1), 21-28.

Blum, L., \& Frieze, C. (2005). The evolving culture of computing. Frontiers: A Journal of Women Studies, $26(1), 110-125$.

Carlson, S. (2006). Wanted: Female computer-science students. Retrieved February 16, 2006, from www.chronicle.com/free/v52/i19/19a03501.htm

Camp, T. (1997). The incredible shrinking pipeline. Communications of the ACM, 40(10), 103-110.

Chicago Public Schools (2006).Chicago Public Schools: Every Child, Every School. Retrieved March 5, 2006, from http://www.cps.k12.il.us/

Connolly, D. A., \& Lindsay, D. S. (1999). The influence of suggestions on children's reports of a unique experience versus an instance of a repeated experience. Applied Cognitive Psychology, 15, 205-223.

Eglash, R. (2002). Race, sex, and nerds: From black geeks to Asian American hipsters. Social Text, 20(2).

Elish, J. (2006). From geek to chic: The changing face of computing. Retrieved May 12, 2006, from www.fsu.edu/news/2006/05/11/geek.chic/

Graham, S., \& Latulipe, C. (2003). CS girls rock: Sparking interest in computer science and debunking the stereotypes. In Proceedings of the 34th SIGCSE Technical Symposium on Computer Science Education (pp.322-326). Reno, Nevada.

Grant, D. M., Knight, L. V., \& Steinbach, T. A. (2006). Fostering technology interest among high school girls. In D. E. Trauth (Ed.), Encyclopedia of gender and information technology (Vol. I, pp. 349-354). Hershey, PA: Idea Group Inc.

Hazzan, O., \& Levy, D. (2006). ACM's attention to women in IT. In E. M. Trauth (Ed.), Encyclopedia of gender and information technology (Vol. I, pp. 7-12). Hershey, PA: Idea Group Inc.

Hecker, D. E. (2005). Occupational employment projections to 2014. Retrieved March 15, 2006, from http://www.bls.gov/opub/mlr/2005/11/art5full.pdf

Holzer, J. (2006). CEOs fret over America's workforce. Retrieved February 21, 2006, from www.Forbes.com/2006/02/08

Indiana University (2006). IU computing women seek to dispel geek mythology. Retrieved November 6, 2006, from www.informatics.indiana.edu/news/news.asp? $\mathrm{id}=328$

Information Technology Association of America. (2005). Untapped talent: Diversity, competition, and America's high tech future. June 21, 2005. Arlington, VA.

Jepson, A., \& Perl, T. (2002). Priming the pipeline. SIGCSE Bulletin, 34(2), 36-39.

Lazowska, E. (2002). Pale and male: 19th century design in a 21st century world. SIGCSE Bulletin, 34(2), $11-12$.

Margolis, J., \& Fisher, A. (2002). Unlocking the clubhouse: Women in computing. Cambridge, MA: MIT Press.

McGee, M. K. (2005). New program aims to woo more kids into IT careers. Retrieved October 1, 2005, from www.informationweek.com/story/showArticle.jhtml

Miliszewska, I., Barker, G., Henderson, F., \& Sztendur, E. (2006). The issue of gender equity in computer science - What students say. Journal of Information Technology Education, 5, 107-120. Retrieved from http://jite.org/documents/Vol5/v5p107-120Miliszewska136.pdf

National Center of Educational Statistics (2005). Digest of Education Statistics. Retrieved January 10, 2006, from http://nces.ed.gov/programs/digest/d02/index.asp 
Newton, S. (2001). Breaking the code: Women confront the promises and the perils of high technology. Women's Studies Quarterly, 29, 71-79.

Sanders, J. (2005). Gender and technology in education: A research review. Retrieved February 12, 2006, from www.josanders.com/pdf/gendertech0705.pdf

Schott, G., \& Selwyn, N. (2000). Examining the "male, antisocial" stereotype of high computer users. Journal of Educational Computing Research, 23(3), 291-303.

Sooriamurthi, R., Sengupta, A., Menzel, S., Moor, K., Stamm, S., \& Borner, K. (2004). Java engagement for teacher training: An experience report. In Proceedings of the Frontiers in Education Conference, (pp. T2D1-6) Savannah, Georgia

Taylor, A. K., \& Kowalski, P. (2004). Naïve psychological science: The prevalence, strength, and sources of misconceptions. The Psychological Record, 54, 15-25.

Thomas, T., \& Allen, A. (2006). Gender differences in students' perceptions of information technology as a career. Journal of Information Technology Education, 5, 165-178. Retrieved from http://jite.org/documents/Vol5/v5p165-178Thomas157.pdf

Weibel, K. (2006). Fewer females in computer science. Retrieved February 16, 2006, from www.purdueexponent.org/index.php/module/Issue/action/Article/article_id/2865

Weinberger, C. J. (2004). Just ask! Why surveyed women did not pursue IT courses or careers. IEEE Technology and Society Magazine, 23(2), 28-35.

Wessa, P. (2006). Free statistics software, Office for Research Development and Education, version 1.1.20. Retrieved March 16, 2006, from http://www.wessa.net/

Williams, L. (2005). Debunking the geek stereotype with software engineering education. Retrieved September 15, 2006 from www.site.uottawa.ca/cseet2005/KeynotesPDF/LaurieWilliamsKeynoteCSEET2005.pdf

Women@SCS. (2006).Women@SCS roadshow. Retrieved October 15, 2006, from http://women.cs.cmu.edu/What/Outreach/Roadshow/index.php

\section{Biography}

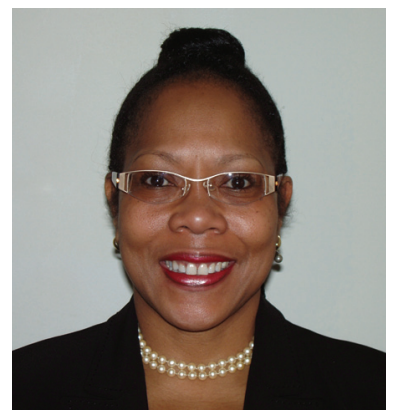

Donna M. Grant is an Assistant Professor at North Carolina Central University. She received her Ph.D. from DePaul University, where she also earned an M.B.A. in Finance and an M.S. in Information Systems. Additionally, she earned a B.S. in Mathematics at Northwestern University. Dr. Grant was the recipient of the Graduate Assistance in Areas of National Need (GAANN) fellowship and the Illinois Graduate Incentive Program (IMGIP) fellowship. As a doctoral student, she was accepted as a member of the Upsilon Pi Epsilon International Computer Science Honors Society and the Phi Kappa Phi Honors Society. In addition, Dr. Grant co-developed a technology summer camp for high school girls called Girls with Engineering Mindz (GEMz). Prior to beginning the doctoral program, she spent 22 years in the IT industry. She worked as a Director of Information Technology at Ameritech and a Director of Process Improvement for the Joint Commission on Accreditation of Healthcare Organizations. 


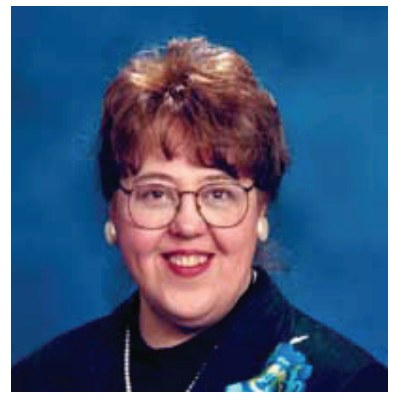

Linda V. Knight is Associate Dean of DePaul University's School of Computer Science, Telecommunications, and Information Systems. She is also Director of DePaul CTI's Center for the Strategic Application of Emerging Technologies (SAET), a research group that explores leveraging new and emerging technology within organizations. She teaches and conducts research in the area of Information Technology strategy, development, and implementation. She is Editor-in-Chief of the Journal of IT Education (www.jite.org), Associate Editor of the Information Resources Management Journal, and MBAA International President-elect. In addition, she is on the Editorial Advisory Board of the Journal of Cases on Information Technology (JCIT), and is a member of the Information Resources Management Association Executive Council. She is also Past President and Fellow of the Society for the Advancement of Information Systems, an affiliate of MBAA International. An entrepreneur and IT consultant, she has held industry positions in IT management and quality assurance management. In addition to a Ph.D. in computer science from DePaul CTI, she holds a B.A. in mathematics and an MBA, both from Dominican University.

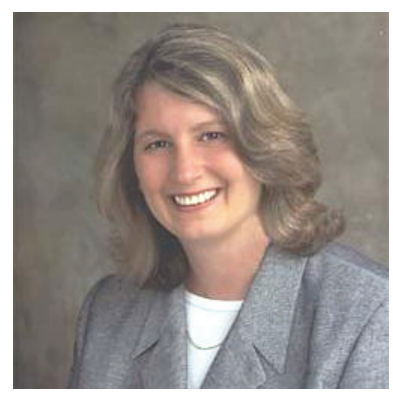

Theresa A. Steinbach is an Assistant Professor at DePaul University. Her primary research interests are system development methodology, project management, ethics and IT education. She advises the Digital Divas, a support network for women in her school, and will conduct a summer camp for high school women with funding from NSF and Hewlett Packard grants. Prior to teaching full-time for DePaul CTI, Terry owned her own consulting firm that specialized in maximizing technology for business growth and profits. 